as I pronounce it, identical to wind-borne riflings of rain above desert light.

Here I am, like God, the pulsing center in a gather of waxwings widening and tightening in their flock against the sky, like God, a wayward thread of cottonwood lifting over fields, forswearing forever, all bones, every place.

\title{
Creation by the Presence of Absence: City Coyote in Rain
}

She's sleek blue neon through the blue of the evening. She's black sheen off the blue of wet streets, blue daunt of suspension in each pendant of rain filling the poplars on the esplanade.

Her blue flank flashes once in the panes of empty windows as she passes. She's faster than lighthouse blue sweeping the seas in circles.

Like the leaping blue of flames burning in an alley barrel, her presence isn't perceived until she's gone.

She cries with fat blue yelps, calls with the scaling calls of the rag men, screeches a siren of howls along the docks below the bridges, wails with the punctuated griefs of drunks and orphans. 
She scuttles under gates, through doors hanging by broken hinges, behind ash bins, into a culvert, shakes off the storm in an explosion of radiance, licks the cold muzzles and genitals of her frenzied pups, gives them her blue teats, closes her yellow eyes.

No one ever sees her face to face, or those who do never know they do, denying her first, pre-empting her lest the place of pattern and time she creates, like the blue of a star long since disintegrated, enter their hearts with all of its implications. 